\title{
Binge ethanol administration enhances the MDMA-induced long-term 5-HT neurotoxicity in rat brain
}

\author{
María Izco • Laura Orio • Esther O'Shea • \\ M. Isabel Colado
}

Received: 16 June 2006 / Accepted: 26 September 2006 / Published online: 18 October 2006

(C) Springer-Verlag 2006

\begin{abstract}
Rationale Ecstasy abuse commonly occurs in hot, overcrowded environments in combination with alcohol. Around $90 \%$ of ecstasy users take ethanol; over $70 \%$ of these users also often drink alcohol at hazardous levels.

Objectives We wished to examine whether binge ethanol administration enhanced the long-lasting 5-HT neurotoxicity induced by 3,4-methylenedioxymethamphetamine (MDMA) in rats maintained at high ambient temperature and the role of acetaldehyde.

Materials and methods Rats were treated with a 4-day ethanol regimen leading to plasma ethanol levels of around $450 \mathrm{mg} / \mathrm{dl}$. On day 5 , rats were placed at $30^{\circ} \mathrm{C}$ and administered MDMA (5 mg/kg). Rectal temperature and hydroxyl radical formation were measured immediately before and up to $6 \mathrm{~h}$ after MDMA. 5-HT concentration and 5-HT transporter density were determined 7 days later. A group of rats received cyanamide $(50 \mathrm{mg} / \mathrm{kg})$ on days 1 and 3 of the 4-day-ethanol inhalation.

Results In ethanol treated rats, MDMA produced a hyperthermic response similar to that observed in controls but enhanced the loss of 5-HT concentration and 5-HT transporter density in the hippocampus. Cyanamide elevated the plasma acetaldehyde concentration fivefold to sevenfold, reduced the MDMA-induced hyperthermia and increased the neuronal damage with neurotoxicity also appearing in the cortex. MDMA increased hydroxyl radical production in the hippocampus, the effect being more marked in rats pre-exposed to ethanol.
\end{abstract}

M. Izco $\cdot$ L. Orio $\cdot$ E. O'Shea $\cdot$ M. I. Colado $(\bowtie)$

Departamento de Farmacologia, Facultad de Medicina,

Universidad Complutense,

Madrid 28040, Spain

e-mail: colado@med.ucm.es
Conclusions Binge ethanol administration enhances the MDMA-induced long-term 5-HT neurotoxicity by a mechanism not related to changes in acute hyperthermia but probably involving hydroxyl radical formation. The magnitude of this effect is more pronounced after increasing plasma acetaldehyde levels by aldehyde dehydrogenase inhibition.

Keywords MDMA · Neurotoxicity · Hyperthermia . 5-HT · 5-HT transporter - Ethanol - Acetaldehyde .

Binge administration
Abbreviations
DHBA dihydroxybenzoic acid
DNPH dinitrophenyl hydrazine
5-HIAA 5-hydroxyindoleacetic acid
MDMA 3,4-methylenedioxymethamphetamine

\section{Introduction}

3,4-Methylenedioxymethamphetamine (MDMA, 'ecstasy') is widely used as a recreational drug by young people despite having been shown to be a neurotoxin in the brains of rodents and non-human primates (Green et al. 2003) and to produce lasting specific memory deficits in humans (Bolla et al. 1998; Verkes et al. 2001; Fox et al. 2002; Verbaten 2003; Soar et al. 2004; Wareing et al. 2000; 2004a,b; Montgomery et al. 2005; Gouzoulis-Mayfrank et al. 2003, 2005). These psychopathological disturbances are probably a consequence of the long-term neurochemical changes induced by the drug (Reneman et al. 2000; Cowan et al. 2003; Daumann et al. 2005). Ecstasy abuse usually takes place at crowded and warm dance clubs and raves in 
the context of multiple drug consumption; alcohol and cannabis being the most common drugs used in combination with ecstasy (Schifano et al. 1998; Winstock et al. 2001; Plan Nacional sobre Drogas 2004). Around 90\% of ecstasy users take ethanol; over $70 \%$ of these users also often drink alcohol at hazardous levels (Winstock et al. 2001). Chronic or excessive alcohol consumption leads to permanent brain damage in both humans and experimental animals and to the impairment of cognitive functions such as learning and memory (Pfefferbaum et al. 1998; White 2003). According to Hunt (1993), binge drinkers who consume at least four or five drinks in a row are particularly susceptible to eventual brain damage. In Spain, about $40 \%$ of male college students (aged 15-34) and a high percentage (20\%) of older adults (aged 35-64) reported binge drinking in a survey covering the whole of 2003 (Plan Nacional sobre Drogas 2004). The same pattern is observed in females, although percentages are lower for the same age intervals.

It was frequently reported that the administration of MDMA to rats produces an acute hyperthermic response and a relatively selective long-term neurotoxic damage to 5HT pathways, having little effect on dopamine containing neurons (Green et al. 2003). The degeneration is reflected by a substantial decrease in the concentration of 5-HT and its metabolite, 5-hydroxyindoleacetic acid (5-HIAA), a reduction in the density of 5-HT uptake sites labelled with $\left[{ }^{3} \mathrm{H}\right]$-paroxetine (Sharkey et al. 1991; Hewitt and Green 1994; Colado et al. 1997a; Sanchez et al. 2001) and a decrease in the immunoreactivity of fine 5-HT axons in the neocortex, hippocampus and striatum (O'Hearn et al. 1988).

The mechanisms involved in producing this neurodegeneration are not totally understood, but evidence indicates that a process of oxidative stress is initiated immediately after MDMA administration. Intracerebral microdialysis in vivo has shown that MDMA induces an increase in the formation of hydroxyl radicals, reflected by a rise in 2,3 dihydroxybenzoic acid (2,3-DHBA) in the hippocampal and striatal dialysates (Colado et al. 1997a; Shankaran et al. 1999). The hydroxyl radical scavenger $\alpha$ phenyl- $N$-tert-butyl nitrone abolishes the MDMA-induced rise in 2,3-DHBA (Colado et al. 1997a) and attenuates damage to 5-HT neurons (Colado and Green 1995; Colado et al. 1997a; Yeh 1999). Additional evidence supporting the existence of an oxidative stress process includes the observation that MDMA increases lipid peroxidation in the brain (Sprague and Nichols 1995; Colado et al. 1997b).

Episodic ethanol intoxication and withdrawal, characteristic of binge alcoholism or chronic ethanol administration, induces substantial neurodegeneration in the hippocampus and entorhinal cortex of the rat (Miki et al. 2000; Zharkovsky et al. 2003; Prendergast et al. 2004;
Baydas and Tuzcu 2005; Hamelink et al. 2005). Several mechanisms were postulated to be involved in ethanol neurodegeneration, some of them also being involved in MDMA-induced neuronal damage. Among the most relevant are excessive glutamatergic activity (Tsai et al. 1995), increased intracellular calcium (Lovinger 1993) and an oxidative stress process (Bondy et al. 1996; Crews et al. 2004) mediated by a rise in oxygen and nitrogen-derived reactive species (Lancaster 1992; Reddy et al. 1999; Huang et al. 2002; Dahchour et al. 2005), a reduction in the activity of the main antioxidant enzymes and an increase in the degree of lipid peroxidation (Somani et al. 1996; Fadda and Rossetti 1998; Reddy et al. 1999; Agar et al. 2003; Thirunavukkarasu et al. 2003).

We have now examined the effect of binge ethanol consumption on the acute hyperthermia and the longlasting loss of 5-HT content and 5-HT transporters induced by a single MDMA administration in rats maintained at high ambient temperature to mimic human ecstasy consumption. The effect of ethanol on the changes induced by MDMA on free radical formation and the possible involvement of acetaldehyde, the main active metabolite of ethanol, in the neurochemical actions of ethanol were also evaluated.

\section{Materials and methods}

Animals and drug administration

Male Dark Agouti rats (150-175 g, Interfauna, Barcelona) were used. They were always housed in groups of six, in conditions of constant temperature $\left(21^{\circ} \mathrm{C} \pm 2^{\circ} \mathrm{C}\right)$ and a $12 \mathrm{~h}$ light/dark cycle (lights on: 07:00 h) and given free access to food and water.

For ethanol treatment rats were placed into 371 chambers and exposed to ethanol vapour or humidified air (controls). Ethanol (absolute, Panreac, Barcelona, Spain) or water was delivered via an osmotic pump (Harvard) into an airtight flask maintained at $42^{\circ} \mathrm{C}$ by a water bath. A constant stream of air $(101 \mathrm{air} / \mathrm{min})$ was passed through the flask, which carried the ethanol or water vapour into the chamber. The flow rate was varied to create different levels of ethanol vapour. This method of ethanol administration permits a control of the timing of ethanol exposure in contrast to the two-bottle free-choice paradigm and allows high blood alcohol levels to be reached that would otherwise require elevated volumes of ethanol injection by the IP route.

MDMA (NIDA, Research Triangle Park, NC, USA) and cyanamide (Sigma, Madrid, Spain) were dissolved in saline $(0.9 \% \mathrm{NaCl})$ and given in a volume of $1 \mathrm{ml} / \mathrm{kg}$. Doses are reported in terms of the base. 
Experimental design

Study 1 Rats were placed in the inhalation chambers and exposed for $3 \mathrm{~h}$ to different flow rates of ethanol $(0.25$ $1.75 \mathrm{ml} / \mathrm{min})$. Plasma ethanol concentration was measured immediately after removal. The goal was to assess whether there was a linear relationship between the speed at which ethanol vapour was pumped into the inhalation chamber and plasma ethanol concentration. This experiment allowed us to choose flow rates producing ethanol plasma concentrations of approximately $450 \mathrm{mg} / \mathrm{dl}$. This level of ethanol was selected to mimic the exposure received by certain sectors of society who indulge in a repeated high level consumption of ethanol in a short interval ("binge" drinking) leading to severe intoxication (Doyle et al. 1994; Parke et al. 1996; Whiteman et al. 2000).

Study 2 Rats were exposed to plasma ethanol concentrations of about $450 \mathrm{mg} / \mathrm{dl}$ before MDMA administration. Similar binge ethanol administration was previously used to mimic a single cycle of binge drinking in humans (Collins et al. 1998; Miki et al. 2000; Obernier et al. 2002a,b; Hamelink et al. 2005). Ethanol or air was pumped into the inhalation chamber at a flow of $1 \mathrm{ml} / \mathrm{min}$ for $3 \mathrm{~h}$ daily during 4 consecutive days. Rectal temperature was measured before placing rats in the inhalation chambers and immediately after removal. Plasma levels of ethanol were quantified daily immediately after the $3 \mathrm{~h}$ ethanol exposure. Then $24 \mathrm{~h}$ after the last ethanol exposure, rats were placed in a room maintained at an ambient temperature of $28-30^{\circ} \mathrm{C}$ (referred to as $30^{\circ} \mathrm{C}$ ) for $2.5 \mathrm{~h}$ before MDMA $(5 \mathrm{mg} / \mathrm{kg}$, IP) injection and for $6 \mathrm{~h}$ after MDMA injection. Rectal temperature was measured for $1 \mathrm{~h}$ before and up to $6 \mathrm{~h}$ after MDMA injection. After that, the rats were placed at $21^{\circ} \mathrm{C}$ and maintained at this temperature until the end of the study. Seven days after MDMA administration, the rats were killed, their brains removed and the concentration of 5-HT and the density of 5-HT uptake sites in the hippocampus and frontal cortex were determined.

Study 3 To evaluate the involvement of free radicals on the changes induced by MDMA, the formation of hydroxyl radicals in the hippocampus of rats exposed and not exposed to ethanol was determined. For that, animals were implanted a guide cannula 3 days before ethanol exposure and dialysis probes inserted in the guide cannulae on the day of MDMA administration (24 h after chamber removal).

Study 4 To study the involvement of acetaldehyde in the changes in MDMA effects induced by ethanol exposure, a separate group of rats exposed to ethanol was injected with cyanamide $(50 \mathrm{mg} / \mathrm{kg}$, IP) or saline $30 \mathrm{~min}$ before placing the rats in the inhalation chambers on days 1 and 3 of the 4 day-exposure. This dose of cyanamide increases acetaldehyde levels compared with those observed in rats receiving only ethanol (Kinoshita et al. 2002). The rest of the experimental protocol was performed in the same way as in study 2 .

Plasma ethanol concentration

Blood ethanol levels were determined every day immediately after the $3 \mathrm{~h}$ ethanol exposure. Samples of $20 \mu \mathrm{l}$ of blood were collected from the tail in heparanized capillary tubes, centifuged at $1500 \times \mathrm{g}$ for $6 \mathrm{~min}$ at $4^{\circ} \mathrm{C}$ (Microcentrifuge MK5, model 01400-00, Analox, UK) and injected in an analyser (AM1, Analox, UK). The rationale of the method consists of ethanol being oxidized by the enzyme alcohol oxidase in the presence of molecular oxygen. Therefore, the rate of oxygen consumption is directly proportional to the alcohol concentration. Plasma ethanol levels were calculated as $\mathrm{mg} / \mathrm{dl}$, using ethanol $300 \mathrm{mg} / \mathrm{dl}$ as standard.

Plasma acetaldehyde concentration

Acetaldehyde was determined by high pressure liquid chromatography (HPLC) using a modification of the method described by Kozutsumi et al. (2002). Briefly, $100 \mu \mathrm{l}$ blood was collected in heparin tubes and deproteinated with perchloric acid ( $3 \mathrm{M}$ ) followed by the addition of sodium acetate $(3 \mathrm{M})$. Blood was centrifuged at $1500 \times \mathrm{g}$ for $10 \mathrm{~min}$ at $4^{\circ} \mathrm{C}$. The supernatant was mixed with $500 \mu \mathrm{l}$ of 2,4-dinitrophenyl hydrazine (5 mM, DNPH) and the mixture was allowed to react for $30 \mathrm{~min}$ at room temperature. A methanol solution of $n$-butyladehydeDNPH $(20 \mu \mathrm{M})$ was added to the reaction as internal standard before purification by a solid-phase C18 cartridge (Sep-Pak ${ }^{\circledR}$ Vac). Columns were conditioned with $2 \mathrm{ml}$ of methanol followed by $2 \mathrm{ml}$ of water. The reaction mixture was loaded onto the column and after washing, the retained acetadehyde-DNPH and internal standard were eluted with $2 \mathrm{ml}$ of methanol. The recovered fraction was dried under a nitrogen stream and reconstituted in $0.1 \mathrm{ml}$ of HPLC mobile phase consisting of acetonitrile and water $(65: 35)$. Both acetaldehyde-DNPH and $n$-butyladehyde-DNPH peaks were detected at an absorbance of $365 \mathrm{~nm}$ with an ultraviolet-visible detector.

Measurement of rectal temperature

Rectal temperature was measured every $30 \mathrm{~min}$ by the use of a digital readout thermocouple (BAT12 thermometer, Physitemp, NJ, USA) with a resolution of $0.1{ }^{\circ} \mathrm{C}$ and 
accuracy of $\pm 0.1{ }^{\circ} \mathrm{C}$ attached to a RET-2 Rodent Sensor, which was inserted $2.5 \mathrm{~cm}$ into the rectum of the rat, the animal being lightly restrained by holding it in the hand. A steady readout was obtained within $10 \mathrm{~s}$ of probe insertion.

Measurement of monoamines and their metabolites in cerebral tissue

The rats were killed by cervical dislocation and decapitation, the brains rapidly removed and the hippocampus and frontal cortex dissected out on ice. Tissue was homogenised and 5-HT and 5-hydroxyindoleacetic acid (5-HIAA) measured by HPLC. Briefly, the mobile phase consisted of $\mathrm{KH}_{2} \mathrm{PO}_{4}(0.05 \mathrm{M})$, octanesulfonic acid $(0.8 \mathrm{mM})$, EDTA $(0.1 \mathrm{mM})$ and methanol (16\%), and was adjusted to $\mathrm{pH} 3.7$ with phosphoric acid, filtered and degassed.

The HPLC system consisted of a pump (Waters 510) linked to an automatic sample injector (Loop $200 \mu \mathrm{l}$, Waters 717 plus Autosampler), a stainless steel reversedphase column (Spherisorb ODS2, $5 \mu \mathrm{m}, 150 \times 4.6 \mathrm{~mm}$ ) fitted with a precolumn, and a coulometric detector (Coulochem II, Esa, USA). The flow rate was $1 \mathrm{ml} / \mathrm{min}$ and the working electrode potential was set at $400 \mathrm{mV}$ with a gain of $500 \mathrm{nA}$. The current produced was monitored by using an integration software package (Unipoint, Gilson).

$\left[{ }^{3} \mathrm{H}\right]$-Paroxetine binding in tissue homogenates

$\left[{ }^{3} \mathrm{H}\right]$-Paroxetine binding was measured by the method described in detail by Hewitt and Green (1994). The animals were killed, the brain rapidly removed and dissected on ice within $2 \mathrm{~min}$. The frontal cortex and hippocampus from individual animals were homogenised in ice-cold Tris- $\mathrm{HCl}(50 \mathrm{mM} ; \mathrm{pH}$ 7.4) containing $\mathrm{NaCl}$ $(120 \mathrm{mM})$ and $\mathrm{KCl}(5 \mathrm{mM})$ using an Ultra-Turrax. The homogenate was centrifuged at $30,000 \times \mathrm{g}$ for $10 \mathrm{~min}$ at $4^{\circ} \mathrm{C}$. The supernatant was discarded and the wash procedure repeated twice. The pellet was finally resuspended in the Tris buffer at a concentration of $10 \mathrm{mg}$ tissue $/ \mathrm{ml}$. To obtain an estimate of the maximal density of $\left[{ }^{3} \mathrm{H}\right]$-paroxetine labeled 5-HT uptake sites, the assay solution $(1 \mathrm{ml})$ contained a saturating concentration of $\left[{ }^{3} \mathrm{H}\right]$-paroxetine $(1 \mathrm{nM})$ and $800 \mu$ tissue preparation with the addition of 5HT $(100 \mu \mathrm{M})$ for determination of non-specific binding. Incubation was for $90 \mathrm{~min}$ at room temperature. Assays were terminated by rapid filtration and counting of the radioactivity by scintillation spectrometry. Previous evidence indicates that MDMA causes a decrease in the $B_{\max }$ for paroxetine binding but does not modify $K_{\mathrm{d}}$ values (Battaglia et al. 1987; Ricaurte et al. 1992). Protein concentrations were measured by the method of Lowry et al. (1951).
Implantation of the microdialysis probe in the hippocampus

Rats were anesthetised with sodium pentobarbital (EutaLender, $40 \mathrm{mg} / \mathrm{kg}$, IP) and secured in a Kopf stereotaxic frame with the tooth bar at $-3.3 \mathrm{~mm}$ below the interaural zero. A guide cannula was implanted in the right hippocampus according to the following coordinates: $+2.2 \mathrm{~mm}$ from the interaural line, $-4.3 \mathrm{~mm}$ lateral and $-4 \mathrm{~mm}$ below the skull (König and Klippel 1963). Cannulae were secured to the skull as described by Baldwin et al. (1994).

On the day of the experiment, the dialysis probes (membrane length: $4.0 \mathrm{~mm} \times 500 \mu \mathrm{m}$; CMA/12, Sweden) were inserted in the guide cannulae such that the membrane protruded its full length from the end of the probe.

Measurement of free radical formation in vivo using microdialysis

Free radical formation in the brain in vivo was measured by the method described in detail by Colado et al. (1997a) with some modifications. The method relies on the fact that hydroxyl free radicals react with salicylic acid to generate 2,3-dihydroxybenzoic acid and 2,5-dihydroxybenzoic acid (2,3-DHBA and 2,5-DHBA). This reaction is utilised by measuring the formation of these compounds in the dialysate of a microdialysis probe implanted in the hippocampus (see above), which is being perfused with salicylic acid (see Chiueh et al. 1992; Giovanni et al. 1995). As 2,5-DHBA is also formed peripherally through salicylate hydroxylation by the cytochrome P450 system, only 2,3-DHBA concentration in the dialysate can be considered as a reliable marker of hydroxyl radical formation in the hippocampus (Halliwell et al. 1991). Probes were perfused with aCSF (KCl: $2.5 \mathrm{mM}$; NaCl: $125 \mathrm{mM} ; \mathrm{MgCl}_{2} \cdot 6 \mathrm{H}_{2} \mathrm{O}$ : $1.18 \mathrm{mM} ; \mathrm{CaCl}_{2} \cdot 2 \mathrm{H}_{2} \mathrm{O}: 1.26 \mathrm{mM} ; \mathrm{NaH}_{2} \mathrm{PO}_{4} \cdot \mathrm{H}_{2} \mathrm{O}$ $0.5 \mathrm{mM} ; \mathrm{Na}_{2} \mathrm{HPO}_{4} \cdot 2 \mathrm{H}_{2} \mathrm{O} 5 \mathrm{mM} ; \mathrm{pH}=6.55$ ) containing salicylic acid $(2.5 \mathrm{mM})$ at a rate of $1 \mu \mathrm{l} / \mathrm{min}$ and samples collected from the freely moving animals at $30 \mathrm{~min}$ intervals. The first $60 \mathrm{~min}$ sample was discarded and the next three $30 \mathrm{~min}$ baseline samples were collected.

The HPLC system consisted of a pump (Waters 510) linked to a manual sample injector (Loop $20 \mu \mathrm{L}$ Rheodyne), a stainless steel reversed-phase column $(250 \times$ $4.6 \mathrm{~mm}, 5 \mu \mathrm{m} \mathrm{C} 8$ Ultracarb, Phenomenex) fitted with a precolumn $(30 \times 4.6 \mathrm{~mm}, 5 \mu \mathrm{m}$ C8 Ultracarb, Phenomenex $)$ and a coulometric detector (Coulochem 5100A) with a 5011 analytical cell. The working electrode potential was set at $400 \mathrm{mV}$ with $1 \mu \mathrm{A}$ gain. The mobile phase consisted of $\mathrm{KH}_{2} \mathrm{PO}_{4}(0.025 \mathrm{M})$, acetonitrile $(20 \%)$ and methanol $(10 \%)$ and was adjusted to $\mathrm{pH} 3.25$ with phosphoric acid, filtered and degassed. The flow rate was $1 \mathrm{ml} / \mathrm{min}$. The 
current produced was monitored by using an integration software package (Unipoint, Gilson).

\section{Statistics}

Data from monoamine and binding studies were analyzed using the one-way ANOVA followed by the NewmanKeuls multiple comparison test when a significant $F$ value was obtained. Statistical analyses of the temperature measurements and dialysis were performed using the statistical computer package BMDP/386 Dynamic (BMDP Statistical Solutions, Cork, Eire). Data were analyzed by the analysis of variance (ANOVA) with repeated measures (program 2V) or, where missing values occurred, an unbalanced repeated measure model (program 5V) was used. Both used treatment as the between-subjects factor and time as the repeated measure. Student $t$ test was used to compare the effect on rectal temperature caused by the exposure to ethanol or air in the inhalation chamber. Differences were considered significant at $p<0.05$. The results of the statistical comparisons are included in the figure legends.

\section{Results}

Study 1. Relationship between the flow rate of ethanol in the inhalation chamber and plasma ethanol concentrations An initial experiment was performed to adjust the ethanol flow rate to achieve high plasma ethanol concentrations. Flow rates of $0.25,0.5,1,1.5$ and $1.75 \mathrm{ml} / \mathrm{min}$ led to the following plasma ethanol levels (measured at the end of the $3 \mathrm{~h}$ exposure period): $26 \pm 6(n=4), 168 \pm 5(n=4), 509 \pm 24$ $(n=4), 675 \pm 9(n=4)$ and $778 \pm 17(n=4)$, respectively. There was a linear relationship $\left(R^{2}=0.98\right)$ between the ethanol flow rate and plasma ethanol levels. Ethanol flow rates of $1 \mathrm{ml} / \mathrm{min}$ were used in the subsequent experiments to achieve daily plasma levels of approximately $450 \mathrm{mg} / \mathrm{dl}$.

Study 2. Effect of intermittent exposure to ethanol on the hyperthermia and neurotoxicity induced by MDMA Table 1 shows the plasma ethanol concentration $(409-480 \mathrm{mg} / \mathrm{dl})$

Table 1 Ethanol concentration in the plasma of rats exposed to ethanol pumped at a flow rate of $1 \mathrm{ml} / \mathrm{min}$ into the vapourization chamber

\begin{tabular}{lllll}
\hline & \multicolumn{4}{l}{ Days of ethanol exposure } \\
\cline { 2 - 5 } & 1 & 2 & 3 & 4 \\
\hline $\begin{array}{c}\text { Plasma ethanol } \\
\text { concentration (mg/dl) }\end{array}$ & $449 \pm 33$ & $409 \pm 20$ & $471 \pm 39$ & $481 \pm 47$ \\
\hline
\end{tabular}

Animals were exposed to ethanol vapour for $3 \mathrm{~h}$ daily on 4 consecutive days. Results are shown as the mean $\pm \operatorname{SEM}(n=12$ rats) measured immediately after the $3 \mathrm{~h}$ period of exposure to ethanol pumped at a rate of $1 \mathrm{ml} / \mathrm{min}$ for 4 days. The average ethanol concentration was $453 \mathrm{mg} / \mathrm{dl}$ (referred to as $450 \mathrm{mg} / \mathrm{dl})$.

Rats exposed to humidified air (control) in the inhalation chambers showed a reduction in rectal temperature of about $1^{\circ} \mathrm{C}$ at the end of each $3 \mathrm{~h}$-daily exposure. Ethanol caused a significant reduction in rectal temperature of approximately $0.5^{\circ} \mathrm{C}$ at the end of the first day of treatment compared with the group exposed to air only ( $36.5 \pm 0.05$ vs $36.0 \pm 0.09, p<0.05)$. In the remaining days of exposure ( 2 to 4 days), the rectal temperature of the rats treated with ethanol was similar to that observed in the rats exposed to air. The temperature inside the chamber $\left(21 \pm 2^{\circ} \mathrm{C}\right)$ did not significantly differ from the room temperature on any of the 4 treatment days.

Ethanol exposure induced a mild ataxia at the end of each of the 3 h-daily treatments compared with control rats exposed to humidified air. Animals appeared to have recovered $30 \mathrm{~min}$ later and did not suffer seizures $24 \mathrm{~h}$ after ethanol exposure (time at which MDMA was injected). These effects were observed visually, not quantified.

Administration of MDMA (5 mg/kg, IP) at a room temperature of $30^{\circ} \mathrm{C}$ produced a sustained hyperthermic response lasting at least $6 \mathrm{~h}$, which reached a peak of $1.5^{\circ} \mathrm{C}$ 30 min after administration (Fig. 1). Hyperthermia was not modified by ethanol exposure during the 4 previous days (Fig. 1). Rats treated with ethanol and injected saline

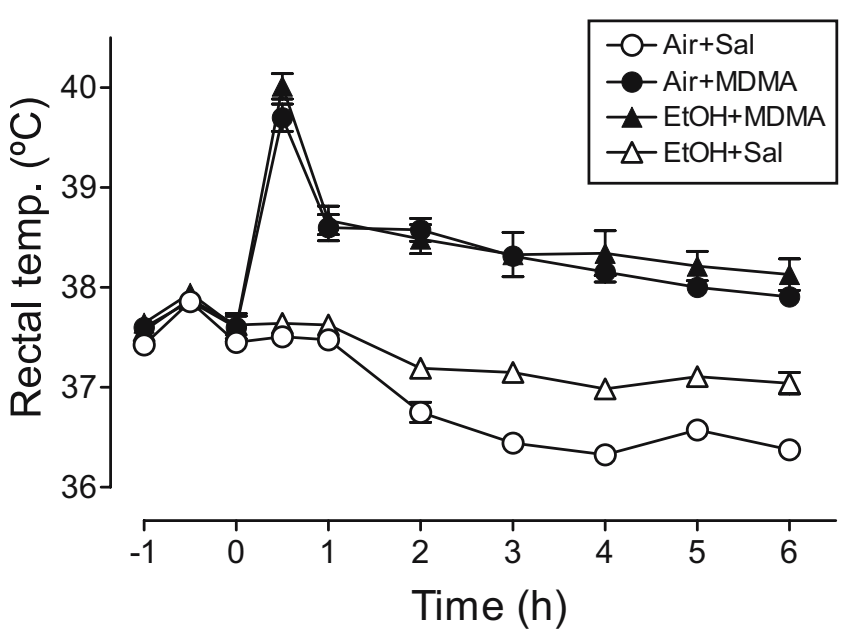

Fig. 1 Hyperthermia induced by MDMA $(5 \mathrm{mg} / \mathrm{kg}$, IP) in rats preexposed to ethanol (EtOH) for $3 \mathrm{~h}$ per day on 4 consecutive days. Then $24 \mathrm{~h}$ after the last $\mathrm{EtOH}$ administration, rats were placed at an ambient temperature of $30^{\circ} \mathrm{C}$ for $2.5 \mathrm{~h}$ before and $6 \mathrm{~h}$ after MDMA injection. Temperature was measured for $1.5 \mathrm{~h}$ before and up to $6 \mathrm{~h}$ after MDMA injection. The arrow shows the time of MDMA administration. Results are shown as the mean $\pm \operatorname{SEM}(n=7-13$ rats). MDMA produced a significant rise in body temperature $(F(1,23)=$ $313.2, p<0.001)$ compared with the saline-injected group. Pretreatment with $\mathrm{EtOH}$ did not modify the hyperthermic response induced by MDMA $(F(1,18)=0.70, p=0.41)$ but increased the body temperature of the saline-injected rats $(F(1,22)=13.59, p<0.01)$ 
showed a rectal temperature higher than the animals injected with saline alone (Fig. 1).

There was a significant decrease in 5-HT concentration and 5-HT transporter density in the hippocampus and frontal cortex 7 days after MDMA injection compared with the saline-injected group (Fig. 2a-d). Pre-exposure to ethanol enhanced both the loss of 5-HT (Fig. 2a) and the reduction in 5-HT uptake density in the hippocampus (Fig. 2c). No change was observed in the frontal cortex (Fig. $2 \mathrm{~b}$ and d). Rats treated with ethanol alone did not show any change on 5-HT concentration and 5-HT transporter density (Fig. 2a-d).

Study 3. Effect of intermittent exposure to ethanol on the hydroxyl radical formation induced by MDMA MDMA administration produced a modest and significant increase

Hippocampus

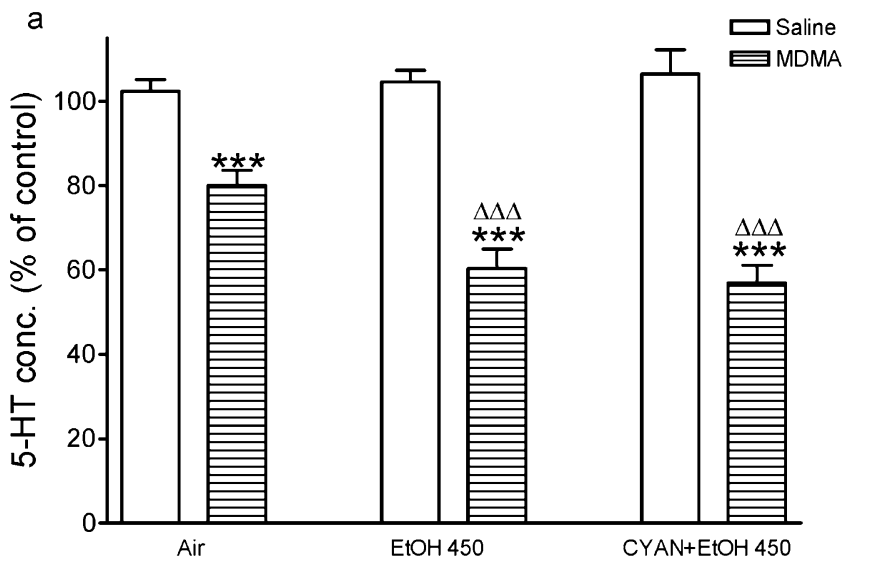

Hippocampus

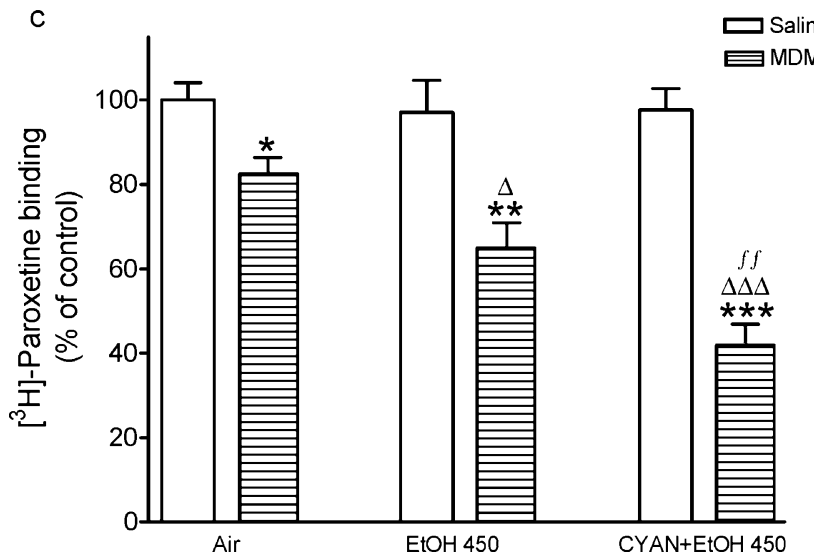

Fig. 2 Changes induced by MDMA ( $5 \mathrm{mg} / \mathrm{kg}$, IP) on $5-\mathrm{HT}$ concentration (a, b) and 5-HT transporter density (c, d) in the hippocampus and frontal cortex of rats pre-exposed to ethanol $(\mathrm{EtOH})$. Animals were exposed to $\mathrm{EtOH}$ for $3 \mathrm{~h}$ per day on 4 consecutive days. A group of rats was given cyanamide $(50 \mathrm{mg} / \mathrm{kg}$, IP) on days 1 and 3 of treatment. On day 5 , all rats were placed at a room temperature of $30^{\circ} \mathrm{C}$ for $2.5 \mathrm{~h}$ before and $6 \mathrm{~h}$ after MDMA injection, animals were killed 7 days after. Results are shown as the mean \pm SEM ( $n=6-12$ rats). Different from the corresponding in the 2,3-DHBA concentration in the hippocampal dialysate. The rise in 2,3-DHBA was approximately 20 $25 \%$ above the concentration seen in saline-injected rats (Fig. 3). Pre-exposure to ethanol significantly enhanced the MDMA-induced rise in the levels of 2,3-DHBA in the hipocampal dialysate and did not modify the content of 2,3DHBA in saline-injected rats (Fig. 3).

Study 4. Effect of raising plasma acetaldehyde concentration on the hyperthermia and neurotoxicity induced by MDMA Rats exposed to ethanol plasma levels of $450 \mathrm{mg} / \mathrm{dl}$ showed acetaldehyde levels between 0.22 and $0.30 \mathrm{mg} / \mathrm{dl}$ immediately after the $3 \mathrm{~h}$ ethanol exposure on each of the 4 days of treatment (Fig. 4a). Administration of cyanamide $(50 \mathrm{mg} / \mathrm{kg}$, IP) on days 1 and 3 of ethanol exposure markedly increased plasma acetaldehyde concentration
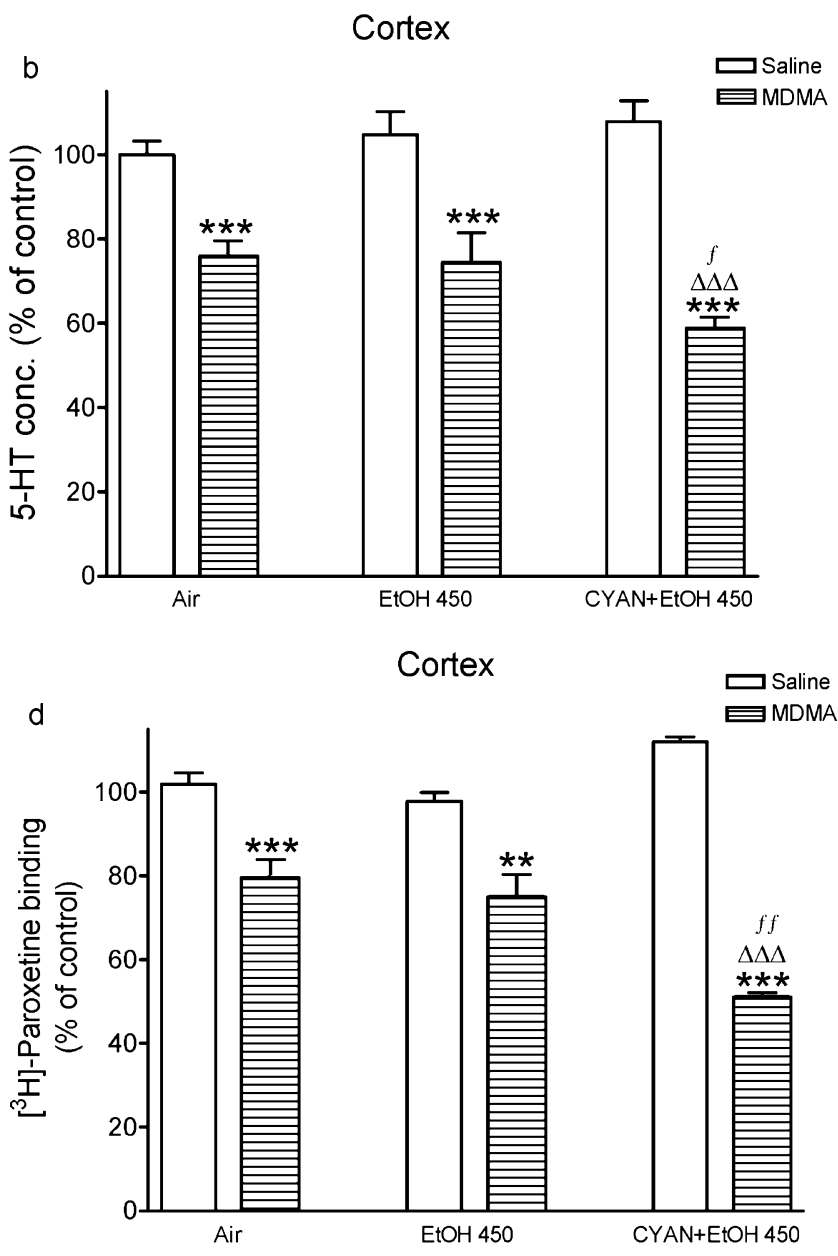

saline-injected rats: ${ }^{*} p<0.05,{ }^{* *} p<0.01,{ }^{* * *} p<0.001$. Different from the MDMA-injected rats pre-exposed to air: ${ }^{\Delta} p<0.05,{ }^{\Delta \Delta \Delta} p<0.001$. Different from the MDMA-injected rats pre-exposed to EtOH: ${ }_{p<0.05,{ }^{f f}} p<0.01$. Absolute values for 5 -HT concentration and $\left[{ }^{3} \mathrm{H}\right]$-paroxetine binding in the hippocampus were $432 \pm 32 \mathrm{ng} / \mathrm{g}$ and $171 \pm 23 \mathrm{fmol} / \mathrm{mg}$ tissue, respectively, and in the cortex were $176 \pm 6 \mathrm{ng} / \mathrm{g}$ and $138 \pm 15 \mathrm{fmol} / \mathrm{mg}$ protein, respectively. The basal levels of 5-HT content and 5-HT transporters were comparable in the three treatment groups for each region 


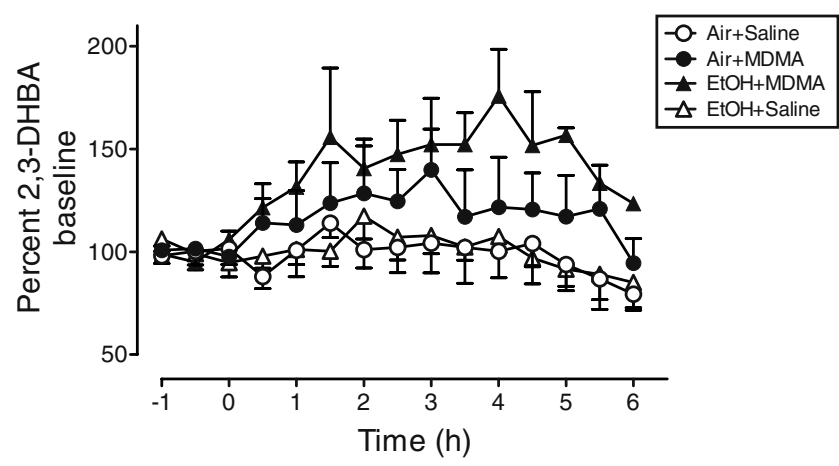

Fig. 3 Changes in the levels of 2,3-dihydroxybenzoic acid (DHBA) in the hippocampal dialysate of rats injected with MDMA $(5 \mathrm{mg} / \mathrm{kg}$, IP) or saline and exposed to ethanol or humidified air $3 \mathrm{~h}$ per day on 4 consecutive days. The arrow shows the time of MDMA administration. MDMA produced a significant increase in the extracellular levels of 2,3 DHBA $(F(1,11)=3.32, p<0.05)$. This effect was enhanced by pre-exposure to ethanol $(F(1,14)=3.42, p<0.05)$. Values are expressed as a percentage of the mean of three measurements before drug administration. Each value is the mean \pm SEM of five to nine experiments. The basal concentrations of 2,3-DHBA in saline-treated rats $(n=6)$ were $8.69 \pm 1.3 \mathrm{pg} / \mu \mathrm{l}$

( $400 \%$ on the first day and $600 \%$ on the third day) compared with animals receiving ethanol alone (Fig. 4a). No change in acetaldehyde levels was observed on days 2 and 4 of ethanol exposure (Fig. 4a). Cyanamide did not alter ethanol plasma levels on any of the 4 days of ethanol exposure (Fig. 4a).

Cyanamide significantly enhanced the ethanol-induced hypothermia with rats showing a rectal temperature $3-3.5^{\circ} \mathrm{C}$ below that observed in animals treated with ethanol alone (Fig. 4b).

Rats treated with cyanamide plus ethanol, $24 \mathrm{~h}$ after ethanol exposure, showed a hyperthermic response to MDMA that was less pronounced than that induced by MDMA in rats treated with ethanol and not given cyanamide (Fig. 5). Rats exposed to ethanol and injected with cyanamide, 7 days after MDMA administration, showed a reduction in cortical 5-HT concentration (Fig. 2b) and 5-HT transporter density in the hippocampus and cortex (Fig. 2c and d), which was greater than that observed in animals exposed to ethanol alone. Rats exposed to ethanol and injected with cyanamide, but not treated with MDMA, did not show any change on 5-HT concentration and 5-HT transporter density (Fig. 2a-d).

\section{Discussion}

This study provides the first evidence indicating that binge administration of ethanol for a restricted period of time enhances the loss of brain 5-HT terminals induced by a moderate dose of MDMA when given at an ambient temperature of $30^{\circ} \mathrm{C}$, which is often the environment in which MDMA is ingested recreationally. Data indicate that animals maintained on a 4-day binge ethanol regimen leading to plasma levels of $450 \mathrm{mg} / \mathrm{dl}$ are more vulnerable to the long-term neurotoxicity induced by MDMA, which is reflected by a more pronounced loss of 5-HT and 5-HT transporter density in the hippocampus compared with those animals inhaling air instead of ethanol vapour.

Ethanol is metabolized to acetaldehyde mainly by the alcohol dehydrogenase pathway both peripherally and in the brain (Raskin and Sokoloff 1970) and, to a lesser extent, by oxidation through the microsomal inducible isoenzyme CYP2D1 (Warner and Gustafsson 1994) and the catalase$\mathrm{H}_{2} \mathrm{O}_{2}$ system (Aragon et al. 1992). Acetaldehyde is subsequently transformed to acetate by aldehyde dehydrogenase. There is much evidence showing that acetaldehyde mediates some of the behavioural and central effects of ethanol, such as headache, nausea, sedation and sleepinduction (Eriksson 2001; Zimatkin et al. 2001a,b). To evaluate the contribution of acetaldehyde to the enhancing effect of ethanol on MDMA-induced neuronal damage, rats were given cyanamide (an inhibitor of aldehyde dehydrogenase) on days 1 and 3 of the 4-day binge ethanol administration and MDMA was injected $24 \mathrm{~h}$ after the final ethanol exposure. According to previous studies, administration of cyanamide (Deitrich et al. 1976; Kinoshita et al. 2002) elevates plasma acetaldehyde concentration between fivefold and sevenfold above that observed in rats treated with ethanol alone and this was confirmed in the current study. In these rats, MDMA produced a more marked loss of 5-HT transporter density in the hippocampus than that observed in those treated with ethanol alone and induced the appearance of damage in the frontal cortex.

The ability of acetaldehyde to cross the blood-brain barrier was repeatedly questioned. From a physicochemical point of view, there is no limiting factor (Quertemont and Tambour 2004). However, it is the presence of aldehyde dehydrogenase in the microvasculature of the brain, which might limit acetaldehyde diffusion by providing a metabolic barrier (Zimatkin 1991). For this reason, the levels of acetaldehyde detected in the brain after ethanol administration are low and mainly derived from the metabolism of ethanol in the brain. However, high plasma acetaldehyde concentrations, such as those reached in the current study after aldehyde dehydrogenase inhibition in the periphery, are able to saturate the metabolic barrier afforded by the brain microvasculature, which in addition is also inhibited by cyanamide administration. In these experimental conditions, elevated brain levels of acetaldehyde with the ability to exert pharmacological activity and enhance MDMA-induced neurotoxicity in rats exposed to ethanol would be expected. Therefore, although after alcohol administration, peripherally produced acetaldehyde could 


\section{a) Plasma EtOH and $\mathrm{AcHO}$ levels}

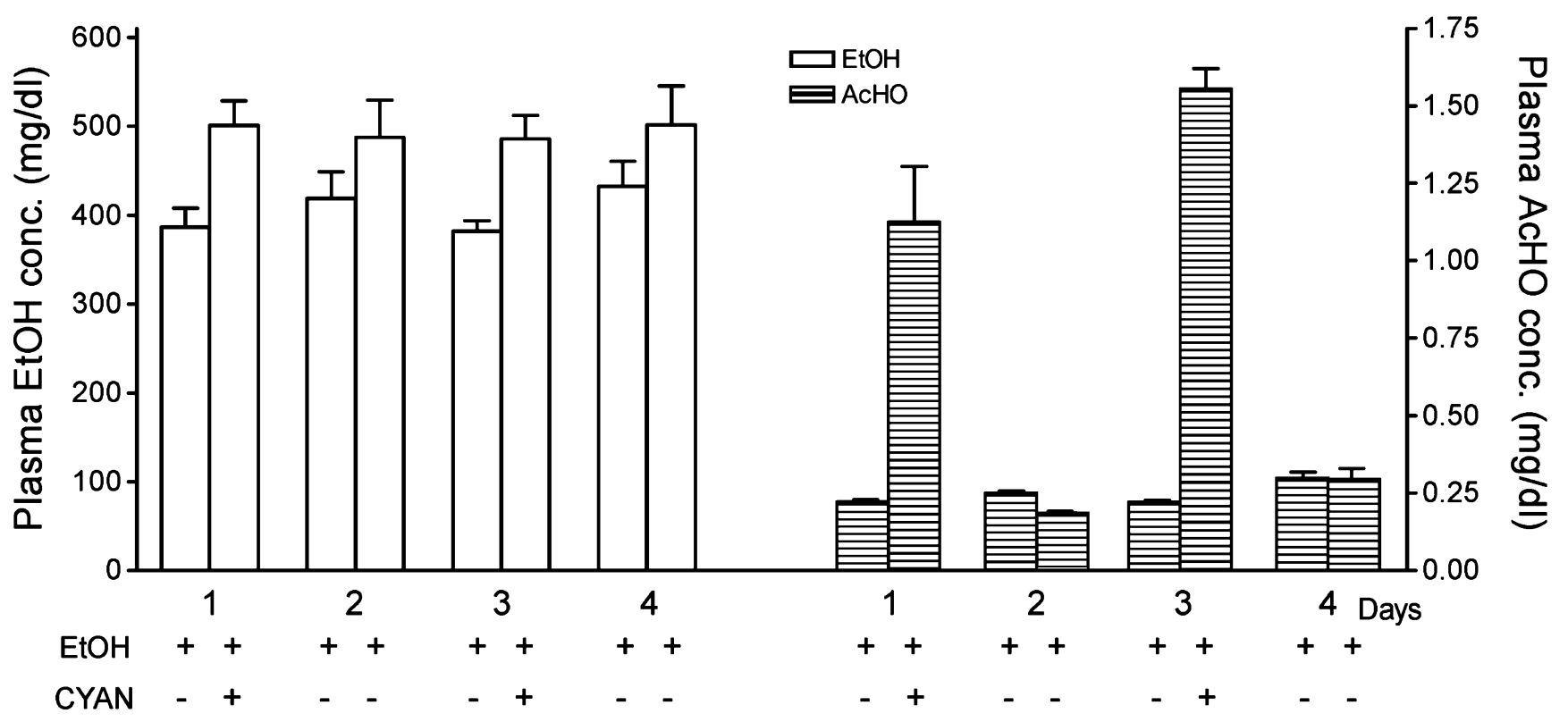

b) Rectal temperature
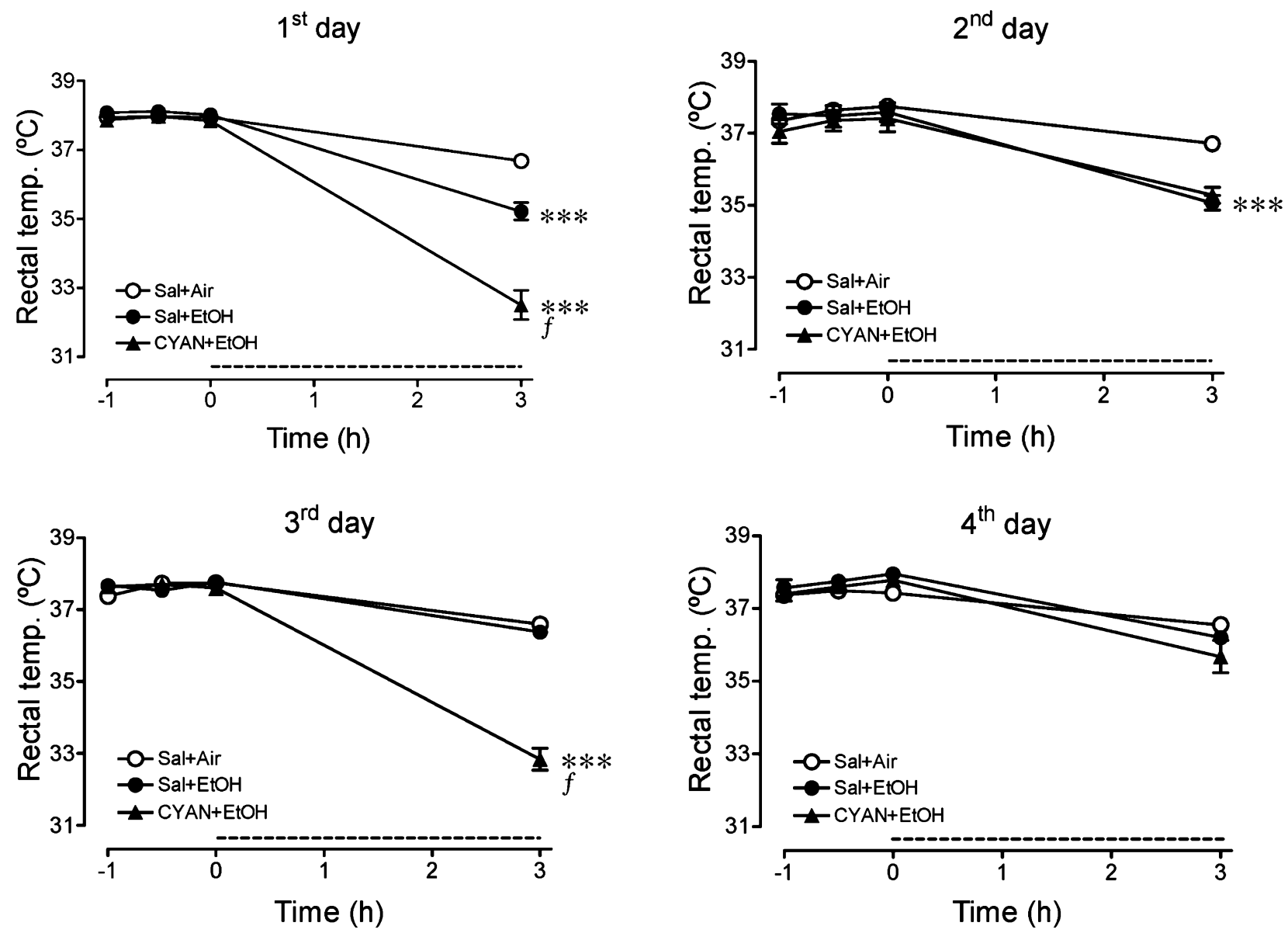
Fig. 4 a) Plasma concentration of ethanol (EtOH) and acetaldehyde $(\mathrm{AcHO})$ in rats exposed to $\mathrm{EtOH}$ pumped at a flow rate of $1 \mathrm{ml} / \mathrm{min}$ into the vaporization chamber and treated with cyanamide. Animals were exposed to $\mathrm{EtOH}$ vapour for $3 \mathrm{~h}$ daily on 4 consecutive days. Cyanamide $(50 \mathrm{mg} / \mathrm{kg}$, IP) was given on days 1 and 3 of $\mathrm{EtOH}$ inhalation. b) Rectal temperature of rats measured for $1.5 \mathrm{~h}$ before EtOH treatment and immediately after removal. Results are shown as the mean \pm SEM ( $n=5-13$ rats). Different from rats exposed to humidified air: $* * * p<0.001$. Different from rats exposed to ethanol only: $f p<0.001$

be rapidly metabolized at the blood-brain barrier before penetrating into brain tissue, in aldehyde dehydrogenase deficient heavy drinkers, the risk of neuronal damage after
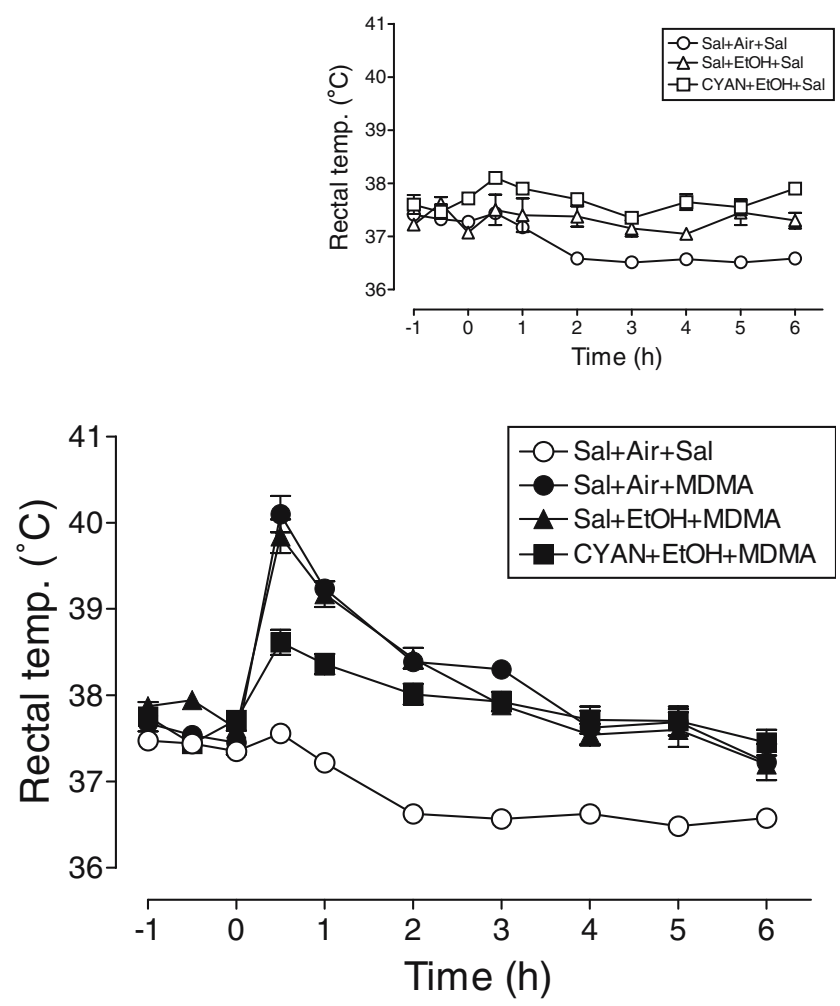

Fig. 5 Hyperthermia induced by MDMA ( $5 \mathrm{mg} / \mathrm{kg}$, IP) in rats preexposed to ethanol (EtOH) for $3 \mathrm{~h}$ per day on 4 consecutive days and injected with cyanamide (CYAN) on days 1 and 3 of EtOH inhalation. Then $24 \mathrm{~h}$ after the last $\mathrm{EtOH}$ administration, rats were placed at a room temperature of $30^{\circ} \mathrm{C}$ for $2.5 \mathrm{~h}$ before and $6 \mathrm{~h}$ after MDMA injection. The temperature was measured for $1.5 \mathrm{~h}$ before and up to $6 \mathrm{~h}$ after MDMA injection. The arrow shows the time of MDMA administration. Results are shown as the mean $\pm \operatorname{SEM}(n=7-12$ rats). MDMA produced a significant rise in body temperature $(F(1,18)=$ 268.25, $p<0.001)$ compared with the saline-injected group. This effect was not modified by EtOH exposure $(F(1,13)=0.84, p=0.84$, n.s. $)$. Rats injected with CYAN on days 1 and 3 of EtOH treatment showed a less pronounced hyperthermic response than animals treated with EtOH only $(F(1,13)=4.52, p<0.05)$. The inset shows the rectal temperature of rats pre-treated with $\mathrm{EtOH}$ and cyanamide and injected with saline instead of MDMA $24 \mathrm{~h}$ later. Rats pre-exposed to EtOH showed an increase in rectal temperature compared with those exposed to air $(F(1,10)=21.92, p<0.001)$. CYAN did not modify the EtOH-induced changes in temperature $(F(1,4)=2.95, p<0.16$, n.s.). The arrow shows the time of saline administration
MDMA could be markedly increased probably due to the presence in the brain of high levels of acetaldehyde.

Cyanamide also inhibits catalase activity both in the liver and in the brain. Therefore, it could be argued that the enhanced neurotoxic effect induced by MDMA found in animals treated with ethanol and cyanamide could be attributed to higher brain levels of ethanol caused by an inhibition of its metabolism through catalase. However, the enzymatic activity of catalase in the liver is $45-60$ fold higher than that observed in the brain (Yang and Lin 2002; Kaushik and Kaur 2003) and the inhibition of this activity in the periphery did not change the plasma levels of ethanol compared with those observed in animals exposed to ethanol alone (this paper). This indicates that ethanol metabolism follows other metabolic pathways. Consequently, there is no reason to assume that the more pronounced toxicity found in animals treated with ethanol and cyanamide is due to higher brain levels of ethanol caused by the inhibition of brain catalase activity.

What seems clear is that repetitive binge ethanol administration does not produce any long-term loss of the 5-HT nerve terminals of the hippocampus and frontal cortex. There is much experimental evidence indicating that binge ethanol administration produces blood alcohol levels similar to or lower than those obtained in the current study causing observable neuronal cell loss and that this effect is especially prominent in the hippocampus, entorhinal and frontal cortex (Collins et al. 1996; Obernier et al. 2002b; Zharkovsky et al. 2003; Hamelink et al. 2005). Neuronal damage was visualized and quantified in the form of argyrophilic neurons with cupric-silver staining techniques (Collins et al. 1996; Hamelink et al. 2005), which, although methods of choice to assess irreversible neurodegeneration caused by a great variety of insults, have the disadvantage that they do not identify the nature of the damaged neuron. In this study, exposure to plasma ethanol levels of up to $450 \mathrm{mg} / \mathrm{dl}$ did not produce any long-term effect on the concentration of 5-HT or the density of 5-HT transporters in the hippocampus and cortex, which indicates an absence of neurotoxic effect on 5-HT containing neurons.

The mechanisms involved in the enhancing effect of ethanol against MDMA neurotoxicity are not totally understood at present. There is evidence that MDMA at the dose of $12.5 \mathrm{mg} / \mathrm{kg}$ given at standard ambient temperature increases the extracellular concentration of 2,3-DHBA and that this effect is involved in the long-term loss of 5-HT terminals (Colado et al. 1997a; Shankaran et al. 1999). The current study shows that this effect is also observed by administration of a lower dose of MDMA $(5 \mathrm{mg} / \mathrm{kg})$ at high ambient temperature and that ethanol treatment enhances the MDMA-induced rise in 2,3-DHBA in the hippocampal dialysate. Acute ethanol administration 
produces a dose-dependent decrease in superoxide dismutase activity in all brain subcellular fractions and in catalase activity in brain mitochondria (Reddy et al. 1999). Superoxide dismutase catalyzes the dismutation of the superoxide anion to hydrogen peroxide $\left(\mathrm{H}_{2} \mathrm{O}_{2}\right)$ (Freeman and Crapo 1982; Fridovich 1989) while catalase uses glutathione in the reduction of $\mathrm{H}_{2} \mathrm{O}_{2}$ to $\mathrm{H}_{2} \mathrm{O}$. Therefore, an increase in free radical formation induced by MDMA could be due to the impairment of the activity of the main cellular antioxidant systems caused by the previous ethanol exposure.

Rats kept in an inhalation chamber and exposed to humidified air showed a reduction in rectal temperature immediately after removal. This effect is not surprising because it is also observed in normal experimental room conditions when the body temperature is monitored throughout the day and mainly when rats are maintained without manipulation during some time (Orio et al. 2004). The exposure to binge plasma ethanol concentrations induced a more pronounced decrease in rectal temperature than that observed in rats exposed to air. This effect is only evident on the first days of treatment. After that, there appeared to be tolerance to the hypothermic effect of ethanol in such a way that rats exposed to ethanol showed a body temperature similar to that observed in rats exposed to air immediately after removal from the chamber. These data are consistent with earlier observations and confirm that the induction of tolerance can appear after one or two ethanol administrations (Crabbe et al. 1979; Maier and Pohorecky 1987; Tampier et al. 2000).

What is striking is that $24 \mathrm{~h}$ after ethanol exposure and when placed at high ambient temperature $\left(30^{\circ} \mathrm{C}\right)$, rats show a body temperature higher than those exposed to air. It has been shown that the acute administration of relatively high doses of ethanol produces a condition of poikilothermia and that the maintenance of the animal at high ambient temperature immediately after ethanol injection elevates the rectal temperature of the animal during the time of heat exposure (Myers 1981). This effect reflects an alteration of the compensatory physiological responses mediating temperature control, including vasodilatation and tachypnea, which occur immediately in response to a thermal challenge. This impairment is sufficient to prevent heat loss and, consequently, to cause a marked hyperthermia if the ambient temperature is elevated.

MDMA increases rectal temperature shortly after peripheral administration. This hyperthermic response being a key factor in the long-term 5-HT neurotoxicity (Sanchez et al. 2001; Orio et al. 2004). However, the changes induced by ethanol in MDMA neurotoxicity do not seem to be related to an effect on the MDMA-induced hyperthermia. Animals exposed to ethanol developed a hyperthermic response similar to that observed in control rats treated with
MDMA alone but nevertheless the loss of 5-HT concentration and 5-HT transporter density in the hippocampus was more pronounced. In addition, when animals are treated with cyanamide and exposed to ethanol, the hyperthermia of MDMA is clearly less than that observed in animals exposed to ethanol and not given cyanamide, but the loss of 5-HT markers in the hippocampus and cortex was more pronounced. Taken together, these data indicate that the enhancing effect of ethanol on MDMA neurotoxicity is not due to an effect related to changes in body temperature.

In summary, this study demonstrates that exposure to binge plasma ethanol concentrations enhances the longterm neuronal damage induced by MDMA and points to an increase in hydroxyl radicals as a possible underlying mechanism. The magnitude of the effect is dependent on plasma acetaldehyde concentration suggesting that the MDMA-induced neurotoxicity could be more pronounced in aldehyde dehydrogenase deficient heavy ethanol drinkers.

Acknowledgements The authors would like to thank Dr. Richard Green for his helpful comments. M.I.C. thanks the Plan Nacional sobre Drogas (Ministerio de Sanidad y Consumo), Ministerio de Ciencia y Tecnologia (Grant SAF2004-02603) and Ministerio de Sanidad y Consumo (Grant G03/005) for the financial support.

All experimental procedures were performed in accordance with the Guidelines for the Care and Use of Laboratory Animals published by the Universidad Complutense (following EU Directive 86/609/EEC).

\section{References}

Agar E, Demir S, Amanvermez R, Bosnak M, Ayyildiz M, Celik C (2003) The effects of ethanol consumption on the lipid peroxidation and glutathione levels in the right and left brains of rats. Int J Neurosci 113:1643-1652

Aragon CM, Rogan F, Amit Z (1992) Ethanol metabolism in rat brain homogenates by a catalase- $\mathrm{H}_{2} \mathrm{O}_{2}$ system. Biochem Pharmacol 44:93-98

Baldwin HA, Williams JL, Snares M, Ferreira T, Cross AJ and Green AR (1994) Attenuation by chlormethiazole administration of the rise in extracellular amino acids following focal ischaemia in the cerebral cortex of the rat. Br J Pharmacol 112:188-194

Battaglia G, Yeh SY, O'Hearn E, Molliver ME, Kuhar MJ, De Souza EB (1987) 3,4-Methylenedioxymethamphetamine and 3,4-methylenedioxyamphetamine destroy serotonin terminals in rat brain: quantification of neurodegeneration by measurement of $\left[{ }^{3} \mathrm{H}\right]$ paroxetine-labeled serotonin uptake sites. J Pharmacol Exp Ther 242:911-916

Baydas G, Tuzcu M (2005) Protective effects of melatonin against ethanol-induced reactive gliosis in hippocampus and cortex of young and aged rats. Exp Neurol 194:175-181

Bolla KI, McCann UD, Ricaurte GA (1998) Memory impairment in abstinent MDMA ("ecstasy") users. Neurology 51:1532-1537

Bondy SC, Guo SX, Adams JD (1996) Prevention of ethanol-induced changes in reactive oxygen parameters by alpha-tocopherol. Alcohol Alcohol 31:403-410

Chiueh CC, Krishna G, Tulsi P, Obata T, Lang K, Huang SJ, Murphy DL (1992) Intracranial microdialysis of salicylic acid to detect hydroxyl radical generation through dopamine autooxidation in 
the caudate nucleus: effect of MPP+. Free Radic Biol Med 13:581-583

Colado MI, Green AR (1995) The spin trap reagent $\alpha$-phenyl- $N$ tert-butyl nitrone prevents 'ecstasy'-induced neurodegeneration of 5-hydroxytryptamine neurons. Eur J Pharmacol 280:343346

Colado MI, O'Shea E, Granados R, Murray TK, Green AR (1997a) In vivo evidence for free radical involvement in the degeneration of rat brain 5-HT following administration of MDMA ('ecstasy') and $p$-chloroamphetamine but not the degeneration following fenfluramine. Br J Pharmacol 121:889-900

Colado MI, O'Shea E, Granados R, Misra A, Murray TK, Green AR (1997b) A study of the neurotoxic effect of MDMA ('ecstasy') on 5-HT neurons in the brains of mothers and neonates following administration of the drug during pregnancy. Br J Pharmacol 121:827-833

Collins MA, Corso TD, Neafsey EJ (1996) Neuronal degeneration in rat cerebrocortical and olfactory regions during subchronic "binge" intoxication with ethanol: possible explanation for olfactory deficits in alcoholics. Alcohol Clin Exp Res 20:284 292

Collins MA, Zou JY, Neafsey EJ (1998) Brain damage due to episodic alcohol exposure in vivo and in vitro: furosemide neuroprotection implicates edema-based mechanism. FASEB J 12:221-230

Cowan RL, Lyoo IK, Sung SM, Ahn KH, Kim MJ, Hwang J, Haga E, Vimal RL, Lukas SE, Renshaw PF (2003) Reduced cortical gray matter density in human MDMA (ecstasy) users: a voxel-based morphometry study. Drug Alcohol Depend 72:225-235

Crabbe JC, Rigter H, Uijlen J, Strijbos C (1979) Rapid development of tolerance to the hypothermic effect of ethanol in mice. J Pharmacol Exp Ther 208:128-133

Crews FT, Collins MA, Dlugos C, Littleton J, Wilkins L, Neafsey EJ, Pentney R, Snell LD, Tabakoff B, Zou J, Noronha A (2004) Alcohol-induced neurodegeneration: when, where and why? Alcohol Clin Exp Res 28:350-364

Dahchour A, Lallemand F, Ward RJ, De Witte P (2005) Production of reactive oxygen species following acute ethanol or acetaldehyde and its reduction by acamprosate in chronically alcoholized rats. Eur J Pharmacol 520:51-58

Daumann J, Fischermann T, Heekeren K, Henke K, Thron A, Gouzoulis-Mayfrank E (2005) Memory-related hippocampal dysfunction in poly-drug ecstasy (3,4-methylenedioxymethamphetamine) users. Psychopharmacology 180:607-611

Deitrich RA, Troxell PA, Worth WS (1976) Inhibition of aldehyde dehydrogenase in brain and liver by cyanamide. Biochem Pharmacol 25:2733-2737

Doyle KM, Bird DA, al-Salihi S, Hallaq Y, Cluette-Brown JE, Goss KA, Laposata M (1994) Fatty acid ethyl esters are present in human serum after ethanol ingestion. J Lipid Res 35:428-437

Eriksson CJ (2001) The role of acetaldehyde in the actions of alcohol (update 2000). Alcohol Clin Exp Res 25:15S-32S

Fadda F, Rossetti ZL (1998) Chronic ethanol consumption: from neuroadaptation to neurodegeneration. Prog Neurobiol 56:385431

Fox HC, McLean A, Turner JJ, Parrott AC, Rogers R, Sahakian BJ (2002) Neuropsychological evidence of a relatively selective profile of temporal dysfunction in drug-free MDMA ("ecstasy") polydrug users. Psychopharmacology 162:203-214

Freeman BA, Crapo JD (1982) Biology of disease: free radicals and tissue injury. Lab Invest 47:412-426

Fridovich I (1989) Superoxide dismutases. An adaptation to a paramagnetic gas. J Biol Chem 264:7761-7764

Giovanni A, Liang LP, Hastings TG, Zigmond MJ (1995) Estimating hydroxyl radical content in rat brain using systemic and intraventricular salicylate: impact of methamphetamine. J Neurochem 64:1819-1825
Gouzoulis-Mayfrank E, Thimm B, Rezk M, Hensen G, Daumann J (2003) Memory impairment suggests hippocampal dysfunction in abstinent ecstasy users. Prog Neuropsychopharmacol Biol Psychiatry 27:819-827

Gouzoulis-Mayfrank E, Fischermann T, Rezk M, Thimm B, Hensen G, Daumann J (2005) Memory performance in polyvalent MDMA (ecstasy) users who continue or discontinue MDMA use. Drug Alcohol Depend 78:317-323

Green AR, Mechan AO, Elliott JM, O'Shea E, Colado MI (2003) The pharmacology and clinical pharmacology of 3,4-methylenedioxymethamphetamine (MDMA, "ecstasy"). Pharmacol Rev 55:463508

Halliwell B, Kaur H, Ingelman-Sundberg M (1991) Hydroxylation of salicylate as an assay for hydroxyl radicals: a cautionary note. Free Radic Biol Med 10:439-441

Hamelink C, Hampson A, Wink DA, Eiden LE, Eskay RL (2005) Comparison of cannabidiol, antioxidants, and diuretics in reversing binge ethanol-induced neurotoxicity. J Pharmacol Exp Ther 314:780-788

Hewitt KE, Green AR (1994) Chlormethiazole, dizocilpine and haloperidol prevent the degeneration of serotonergic nerve terminals induced by administration of MDMA ('ecstasy') to rats. Neuropharmacology 33:1589-1595

Huang M, Liu W, Li Q, Wu CF (2002) Endogenous released ascorbic acid suppresses ethanol-induced hydroxyl radical production in rat striatum. Brain Res 944:90-96

Hunt WA (1993) Are binge drinkers more at risk of developing brain damage? Alcohol 10:559-561

Kaushik S, Kaur J (2003) Chronic cold exposure affects the antioxidant defense system in various rat tissues. Clin Chim Acta 333:69-77

Kinoshita H, Jessop DS, Roberts DJ, Ameno K, Ijiri I, Hishida S, Harbuz MS (2002) Effects of acetaldehyde on c-fos mRNA induction in the paraventricular nucleus following ethanol administration. Alcohol Alcohol 37:432-435

König JFR, Klippel RA (1963) The rat brain. A stereotaxic atlas of the forebrain and lower parts of the brain stem. Robert E. Krieger, New York

Kozutsumi D, Arita M, Kawashima A, Adachi M, Takami M (2002) An improved method for acetaldehyde determination in blood by high-performance liquid chromatography and solid-phase extraction. J Chromatogr Sci 40:477-482

Lancaster FE (1992) Alcohol, nitric oxide, and neurotoxicity: is there a connection?-a review Alcohol Clin Exp Res 16:539-541

Lovinger DM (1993) High ethanol sensitivity of recombinant AMPAtype glutamate receptors expressed in mammalian cells. Neurosci Lett 159:83-87

Lowry OH, Rosebrough NJ, Farr AL, Randall RJ (1951) Protein measurement with the folin phenol reagent. J Biol Chem 193:265-275

Maier DM, Pohorecky LA (1987) The effect of repeated withdrawal episodes on acquisition and loss of tolerance to ethanol in ethanol-treated rats. Physiol Behav 40:411-424

Miki T, Harris SJ, Wilce P, Takeuchi Y, Bedi KS (2000) Neurons in the hilus region of the rat hippocampus are depleted in number by exposure to alcohol during early postnatal life. Hippocampus 10:284-295

Montgomery C, Fisk JE, Newcombe R, Murphy PN (2005) The differential effects of ecstasy/polydrug use on executive components: shifting, inhibition, updating and access to semantic memory. Psychopharmacology 182:262-276

Myers RD (1981) Alcohol's effect on body temperature: hypothermia, hyperthermia or poikilothermia? Brain Res Bull 7:209-220

Obernier JA, Bouldin TW, Crews FT (2002a) Binge ethanol exposure in adult rats causes necrotic cell death. Alcohol Clin Exp Res 26:547-557 
Obernier JA, White AM, Swartzwelder HS, Crews FT (2002b) Cognitive deficits and CNS damage after a 4-day binge ethanol exposure in rats. Pharmacol Biochem Behav 72:521-532

O'Hearn E, Battaglia G, De Souza EB, Kuhar MJ, Molliver ME (1988) Methylenedioxyamphetamine (MDA) and methylenedioxymethamphetamine (MDMA) cause selective ablation of serotonergic axon terminals in forebrain immunocytochemical evidence for neurotoxicity. J Neurosci 8:2788-2803

Orio L, O'Shea E, Sanchez V, Pradillo JM, Escobedo I, Camarero J, Moro MA, Green AR, Colado MI (2004) 3,4-Methylenedioxymethamphetamine increases interleukin-1beta levels and activates microglia in rat brain: studies on the relationship with acute hyperthermia and 5-HT depletion. J Neurochem 89:1445-1453

Parke T, Simpson D, Mitchell R, MacCallum R, Campbell-Hewson G, Steedman D (1996) Blood alcohol and cardiac arrest. Resuscitation 32:199-202

Pfefferbaum A, Sullivan EV, Rosenbloom MJ, Mathalon DH, Lim KO (1998) A controlled study of cortical gray matter and ventricular changes in alcoholic men over a 5-year interval. Arch Gen Psychiatry 55:905-912

Plan Nacional sobre Drogas (2004) Observatorio Español sobre drogas. Informe

Prendergast MA, Harris BR, Mullholland PJ, Blanchard JA 2nd, Gibson DA, Holley RC, Littleton JM (2004) Hippocampal CA1 region neurodegeneration produced by ethanol withdrawal requires activation of intrinsic polysynaptic hippocampal pathways and function of $N$-methyl-D-aspartate receptors. Neuroscience 124:869-877

Quertemont E, Tambour S (2004) Is ethanol a pro-drug? The role of acetaldehyde in the central effects of ethanol. Trends Pharmacol Sci 25:130-134

Raskin NH, Sokoloff L (1970) Alcohol dehydrogenase activity in rat brain and liver. J Neurochem 17:1677-1687

Reddy SK, Husain K, Schlorff EC, Scott RB, Somani SM (1999) Dose response of ethanol ingestion on antioxidant defense system in rat brain subcellular fractions. Neurotoxicology 20:977-987

Reneman L, Booij J, Schmand B, van den Brink W, Gunning B (2000) Memory disturbances in "ecstasy" users are correlated with an altered brain serotonin neurotransmission. Psychopharmacology 148:322-324

Ricaurte GA, Martello AL, Katz JL, Martello MB (1992) Lasting effects of ( \pm )-3,4-methylenedioxymethamphetamine (MDMA) on central serotonergic neurons in nonhuman primates: neurochemical observations. J Neurochem 261:616-622

Sanchez V, Camarero J, Esteban B, Peter MJ, Green AR, Colado MI (2001) The mechanisms involved in the long-lasting neuroprotective effect of fluoxetine against MDMA ('ecstasy')induced degeneration of 5-HT nerve endings in rat brain. Br J Pharmacol 134:46-57

Schifano F, Di Furia L, Forza G, Minicuci N, Bricolo R (1998) MDMA ('ecstasy') consumption in the context of polydrug abuse: a report on 150 patients. Drug Alcohol Depend 52:85-90

Shankaran M, Yamamoto BK, Gudelsky GA (1999) Involvement of the serotonin transporter in the formation of hydroxyl radicals induced by 3,4-methylenedioxymethamphetamine. Eur J Pharmacol 385:103-110

Sharkey J, McBean DE, Kelly PA (1991) Alterations in hippocampal function following repeated exposure to the amphetamine derivative methylenedioxymethamphetamine ('ecstasy'). Psychopharmacology 105:113-118

Soar K, Parrott AC, Fox HC (2004) Persistent neuropsychological problems after 7 years of abstinence from recreational ecstasy (MDMA): a case study. Psychol Rep 95:192-196
Somani SM, Husain K, Diaz-Phillips L, Lanzotti DJ, Kareti KR, Trammell GL (1996) Interaction of exercise and ethanol on antioxidant enzymes in brain regions of the rat. Alcohol 13:603610

Sprague JE, Nichols DE (1995) The monoamine oxidase-B inhibitor L-depenyl protects against 3,4-methylenedioxymethamphetamine-induced lipid peroxidation and long-term serotonergic deficits. J Pharmacol Exp Ther 273:667-673

Tampier L, Quintanilla ME, Mardones J (2000) Acute tolerance, alcohol sensitivity and drinking pattern in the F2 generation of UChA and UChB rats. J Stud Alcohol 61:647-651

Thirunavukkarasu V, Anuradha CV, Viswanathan P (2003) Protective effect of fenugreek (Trigonella foenum graecum) seeds in experimental ethanol toxicity. Phytother Res 17:737-743

Tsai G, Gastfriend DR, Coyle JT (1995) The glutamatergic basis of human alcoholism. Am J Psychiatry 152:332-340

Verbaten MN (2003) Specific memory deficits in ecstasy users? The results of a meta-analysis. Hum Psychopharmacol 18:281290

Verkes RJ, Gijsman HJ, Pieters MS, Schoemaker RC, de Visser S, Kuijpers M, Pennings EJ, de Bruin D, Van de Wijngaart G, Van Gerven JM, Cohen AF (2001) Cognitive performance and serotonergic function in users of ecstasy. Psychopharmacology 153:196-202

Wareing M, Fisk JE, Murphy PN (2000) Working memory deficits in current and previous users of MDMA ('ecstasy'). Br J Psychol 91:181-188

Wareing M, Fisk JE, Murphy P, Montgomery C (2004a) Verbal working memory deficits in current and previous users of MDMA. Hum Psychopharmacol 19:225-234

Wareing M, Murphy PN, Fisk JE (2004b) Visuospatial memory impairments in users of MDMA ('ecstasy'). Psychopharmacology (Berl) 173:391-397

Warner M, Gustafsson JA (1994) Effect of ethanol on cytochrome P450 in the rat brain. Proc Natl Acad Sci USA 91:10191023

White AM (2003) What happened? Alcohol, memory blackouts, and the brain. Alcohol Res Health 27:186-196

Whiteman PJ, Hoffman RS, Goldfrank LR (2000) Alcoholism in the emergency department: an epidemiologic study. Acad Emerg Med 7:14-20

Winstock AR, Griffiths P, Stewart D (2001) Drugs and the dance music scene: a survey of current drug use patterns among a sample of dance music enthusiasts in the UK. Drug Alcohol Depend 64:9-17

Yang CY, Lin MT (2002) Oxidative stress in rats with heatstrokeinduced cerebral ischemia. Stroke 33:790-794

Yeh SY (1999) N-tert-butyl-alpha-phenylnitrone protects against 3,4methylenedioxymethamphetamine-induced depletion of serotonin in rats. Synapse 31:169-177

Zharkovsky T, Kaasik A, Jaako K, Zharkovsky A (2003) Neurodegeneration and production of the new cells in the dentate gyrus of juvenile rat hippocampus after a single administration of ethanol. Brain Res 978:115-123

Zimatkin SM (1991) Histochemical study of aldehyde dehydrogenase in the rat CNS. J Neurochem 56:1-11

Zimatkin SM, Liopo AV, Satanovskaya VI, Bardina And LR, Deitrich RA (2001a) Relationship of brain ethanol metabolism to the hypnotic effect of ethanol. II: studies in selectively bred rats and mice. Alcohol Clin Exp Res 25:982-988

Zimatkin SM, Liopo AV, Slychenkov VS, Deitrich RA (2001b) Relationship of brain ethanol metabolism to the hypnotic effect of ethanol. I: studies in outbred animals. Alcohol Clin Exp Res 25:976-981 